\title{
Current Situation and Communicative Translation Strategies of Chinese-English Public Signs Translation
}

\author{
Ma Qinhua \\ School of Foreign Studies, Xi'an University, Shaanxi, China, 710065
}

Keywords: public signs; translation strategies; communication tools

\begin{abstract}
With the increasing frequency of international exchanges, the importance of Chinese and English public signs is becoming more and more obvious. However, due to the cultural differences between English and Chinese and other reasons, the present situation of Chinese-English public signs translation is not optimistic, and there are some obvious problems. Therefore, how to strengthen the translation of Chinese-English public signs is particularly important. This paper summarizes the introduction of Chinese-English public signs, the current situation of Chinese-English translation of public signs and communicative translation strategies of public signs.
\end{abstract}

Public signs can be seen everywhere in life, and Chinese-English public signs play a great role in the process of international communication. Public signs are a kind of text which can show people with special characteristics who want to achieve a certain communicative purpose. They are widely used. In the process of international cultural exchange, English has become a universal tool of international communication. Chinese-English public signs are very common in our country, such as parking lots, billboards, road signs, warnings and so on. However, due to various reasons, there are some obvious problems in the translation of Chinese-English public signs, such as language inappropriateness and errors, information tampering and loss, so effective measures must be taken to improve the translation of Chinese-English public signs.

\section{Introduction of public signs and Chinese-English public signs}

Public signs are a special style of writing. It refers to the public to see them in public places in order to achieve a special communicative purpose. Public signs are a very common practical language in people's life, which has been widely used in people's lives. Public signs can be seen in almost all public places. It is an international capital. Language environment and humanistic environment of city and international tourism destination are important components. Public signs have a certain practical significance in people's life, especially for tourists. However, if the translation of public signs is improper or misunderstood, it will lead to some serious consequences. At the same time, it will damage the image of a city, and international tourists will bring many inconveniences.

Chinese-English public signs are a more specific kind of public signs. They refer to a special style of translation between Chinese and English. Today, with the increasingly close international exchanges, English has been widely used as a communicative language in many countries. It is 
precisely because of this that Chinese-English public signs can be seen everywhere in China.

\section{An Analysis of the Current Situation of Translation of Public Signs in Contemporary Chinese and English}

In order to understand the current situation of Chinese-English translation of public signs, this paper summarizes and analyses the translation of public signs in X city through searching and reading relevant materials, and concludes that the main types of errors are complete Pinyin identification, over-translation, grammatical errors, spelling errors, name inconsistency, Chinese English, Random translation, omission translation, inaccurate expression and Mixed use of Chinese and English. The detailed statistical results of mixed use of English are shown in the following table:

Table 1. Translation of Public Signs in X City

\begin{tabular}{|c|c|c|c|c|c|}
\hline type & $\begin{array}{l}\text { Number of } \\
\text { copies }\end{array}$ & Percentage (\%) & type & $\begin{array}{l}\text { Number } \\
\text { of copies }\end{array}$ & Percentage (\%) \\
\hline Chinese English & 194 & 16.3 & Random translation & 192 & 16.1 \\
\hline Pinyin logo & 180 & 15.1 & Over Translation & 42 & 3.5 \\
\hline $\begin{array}{l}\text { Name is not } \\
\text { uniform }\end{array}$ & 90 & 7.6 & Missing translation & 94 & 7.9 \\
\hline Syntax error & 42 & 3.5 & $\begin{array}{c}\text { Inaccuracy of } \\
\text { expression }\end{array}$ & 185 & 15.5 \\
\hline $\begin{array}{l}\text { Spelling } \\
\text { mistakes }\end{array}$ & 61 & 5.1 & $\begin{array}{l}\text { Mixed use of Chinese } \\
\text { and English }\end{array}$ & 110 & 9.2 \\
\hline
\end{tabular}

\subsection{Information loss and tampering in Chinese and English public signs are serious}

Although Chinese and English public signs have been widely used and paid attention to, there are also some problems to be solved urgently in the process of their application. The first problem is the loss of information and tampering of Chinese and English public signs. For example, in many places of entertainment, we can see the public signs of "tourists stop", which are translated as "Guest go no further" or "Stop, Guests, Stop Here" in many places, but anyone who has a little common sense of English will find that such Chinese-English translation does not follow the translation principles, nor does it conform to them. Corresponding English grammar and word order are literal translations of Chinese, which will cause foreign tourists to misunderstand other meanings and make a lot of jokes. For example, many riverside signs warn people not to fall close to the water source in order to avoid accidental falling. The corresponding Chinese-English public signs are translated as "Please mind falling water" or "Carefully fall into the river" in English, which will make foreigners think that they are "please mind falling water" or "Carefully fall into the river". Watch out for the water falling from the sky, not the meaning of falling.

\subsection{The inappropriate translation of information is far from the original meaning.}

There are many common problems in the translation of Chinese-English public signs. In addition to the problems of information loss and tampering in the above-mentioned Chinese-English public signs, there is also a more significant problem - inappropriate translation of information and far from the original meaning. The main reason for this phenomenon is that the staff lacks basic language skills. Similarly, for example, some staff members translate "police affairs station" into "police affairs station", "public toilet" into "public Toilet" and "safe exit" into "EXIT GATE". This 
phenomenon can be seen everywhere. Moreover, such a translation is obviously complementary, and foreigners can not be very good. Understanding what it means will also lead to the misunderstanding that the level of translation in our country is very backward. Such inappropriate language errors will cause great communication barriers for foreign guests, so we must pay full attention to this problem, and improve and solve it in time. As shown in the following figure:
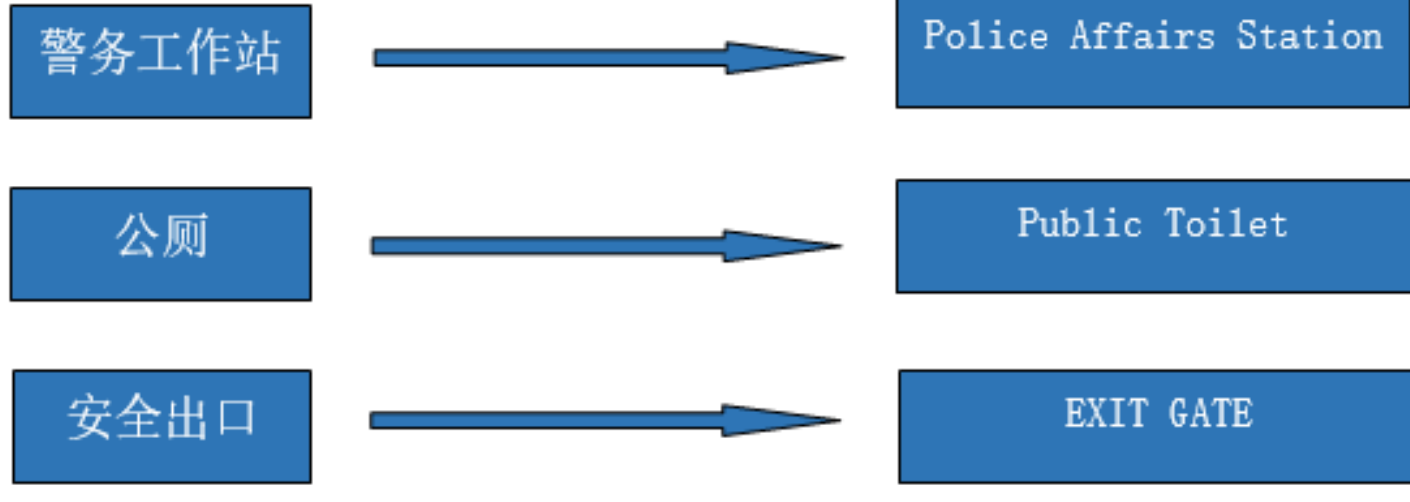

\section{Pub1ic Toilet}
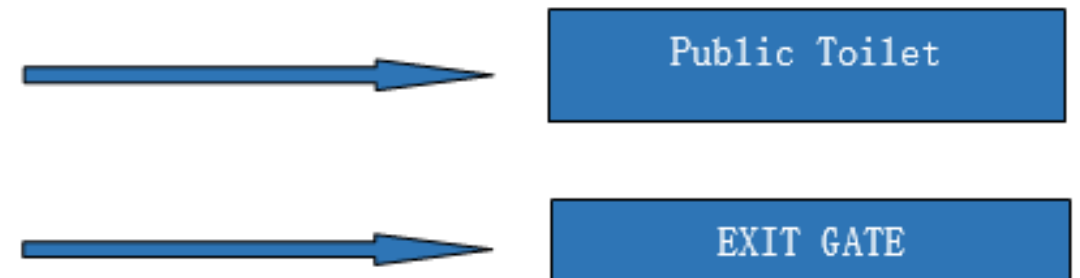

EXIT GATE

Figure 2

\subsection{The making of Chinese and English public signs is too careless}

Due to the frequent carelessness in making Chinese and English public signs, it is also a common problem in the process of translating and making Chinese and English public signs. Because a large part of the Chinese and English public signs staff in our country do not know English very well and have not learned English systematically, some mistakes will inevitably occur in the process of making public signs. For example, translating the smoking room into "SMOKINGROOM". This spelling error makes foreigners very confused and confused. Solution. If this problem can not be solved as soon as possible, it will seriously affect the views of foreign tourists on Chinese cities, and to a certain extent, affect the international image of our country, and bring many disadvantages to the dissemination of tourism culture and the promotion of tourism development.

\section{Suggestions on the Approaches to Communicative Translation of Contemporary Public Signs}

\subsection{Full recognition and understanding of public signs}

Semantic translation and communicative translation are two basic strategies of New mark's translation theory. Compared with semantic translation, communicative translation is oriented towards the target language readers, aiming at conveying information rather than replicating a large number of linguistic information, so as to help readers understand and think better. In order to solve a series of translation problems in Chinese-English public signs, it is necessary for the translator to have a full understanding of the signs. Only after a thorough understanding can he understand the importance of his own work, so as to improve his working ability, efficiency and quality.

The characteristics of public signs can be divided into three points: 1. Nouns, gerunds, abbreviations and phrases should be used extensively in public signs to make the slogans shorter, more concise and easy to understand; 2. Public signs generally do not choose to use uncommon words to reduce readers' difficulties and obstacles in reading or communication, so they should be as popular as possible. Vocabulary; 3. The text of public signs should be shared with common signs, so that readers can get better information to be conveyed by public signs. Therefore, only when the translator fully understands these characteristics of public signs and conveys information according 
to the language, culture and pragmatic habits of the target language readers, can the staff design and produce more standard and accurate signs.

\subsection{Improving the translator's translation literacy and ability}

At present, problems such as ministration, ambiguous semantics, spelling and grammatical errors in public signs translation must be tackled from the source to improve the overall level and quality of translators. Public sign translation is not only a simple linguistic transformation, but also a continuation and regeneration of the source text. Translators should not only improve their translation accomplishment, understand the history, culture and human geography of the target language country, but also decode, analyze and re-code the source text of signs from the perspective of the target language reader, so as to improve their translation skills. Only in this way can the translation of public signs get out of the bottleneck and become an effective medium of communication in public places.

\subsection{Fully grasp the cultural differences between English and Chinese}

When discussing many problems in public signs, it is not difficult to find the differences between Chinese and English, the cultural connotations between China and the West, and the logic differences of language users, all of which make the translation of public signs more difficult. Because each language is the result of thousands of years' precipitation by a country or even a nation, and each country has a very different history of development, and the development of language also changes with the development of the nation. Therefore, in the process of translating public signs, translators must fully grasp the cultural differences between English and Chinese, so that public signs can bring more exquisite tourism experience to foreign friends.

\subsection{Strictly abide by the principle of borrowing and translating public signs}

When translating public signs, the staff must fully express the intention of the public signs. This requires the exploration and research of the pragmatic meaning of the public signs. Only by doing this step can the public signs be translated accurately. In this process, the staff should absolutely avoid looking at the text and meaning, and consult some words which can not fully understand their meaning, so as to ensure the correctness of translation. At the same time, we should strictly abide by its principles in the process of borrowing and translating. At the same time, although some public signs express their meaning relatively accurately, the translation is more rigid, which can make people feel unfriendly. Therefore, such translation is also a failure and must be improved.

\subsection{Fully understanding readers' cultural reading habits}

The use of Chinese and English public signs is mainly for the needs of foreigners living in China. However, because foreigners themselves and the living environment of our people are very different, there are great differences in living habits, ways of thinking, language expression and other aspects, which to a large extent makes everyone's interpretation of public signs. They all have their own different understandings. Therefore, if foreigners want to better understand the intention conveyed by public signs, it is necessary for readers to have a thorough understanding and study of cultural habits, so as to understand the cultural differences more comprehensively. Moreover, it is necessary to adopt common local language habits for translation, rather than literal translation for convenience. In addition to these, translation staff should constantly improve their work quality and ability, through participating in various forms of training to continuously improve their self-ability so as to 
meet the needs of social development, thus helping foreigners better understand the meaning of public signs.

\section{Conclusion}

The purpose of C-E translation of public signs is to provide more convenience for people's life. However, at present, there are some problems that need to be solved urgently. If it is not solved in time, it will seriously affect the role of public signs in C-E translation. Therefore, the relevant departments should face up to this problem, adopt various translation techniques. It is also necessary to improve staff's translation level and understanding of foreign cultures. In order to better create a better language communication environment for foreign friends. Then it can strengthen and improve the communication ability between our country and foreign countries.

\section{References}

[1] Bu Ding. Current Situation of Chinese-English Public Sign Translation and Communicative Translation Strategies [J]. Prospects for Science and Technology, 2014 (16).

[2] Li Na, Dong Hui. The present situation of Chinese-English public signs translation and its communicative translation strategies [J]. Chicle, 2015 (7). The present situation of Chinese-English public signs translation and its communicative translation strategies are discussed.

[3] Ba Li. A Study of Chinese-English Translation of Public Signs from the Perspective of Communicative Translation [D]. Manchurian: Ninja University, 2015.

[4] Huang Debian, Du Xiaoping. Standardization of Public Sign Translation [J]. Terminology Standardization and Information Technology, 2011 (4).

[5] Lin Hipping. Current situation and Countermeasures of translation of tourism public signs in Deafening [J]. Journal of Deafening Teachers College, 2012 (4). 